\title{
Size Effect in Strain Limits of Medium Strength Steel
}

\begin{abstract}
The test results of a larger research project on the strain at failure for a diversity of steel specimens and parameters were evaluated with respect to the influence of the volume of the specimens. The evaluation was based on the statistical Weibull distribution. It could be shown that a clear influence of specimen volume on limit strains is present also in steel and that the effect can be described by a Weibull two-parameter function. The results indicate that limit strains are dependent on one-dimensional parameters such as length or thickness rather than on three-dimensional volume.
\end{abstract}

KEYWORDS: ductility, Weibull, size effect, strain limit, steel

\section{Introduction}

In the assessment of the safety of nuclear power plants, new scenarios have to be taken into account; for example, the smelting of the fuel rods and their cladding tubes and the impact of this molten mass towards the pressure vessel head after an internal explosion. If this rather unlikely scenario were assessed by the established design rules, an unduly conservative design would be the consequence. To improve this situation, new possibilities were looked for-e.g., the use of a ductility reserve. In conservative design the material is loaded only to a part of the elastic limit (e.g., $0.6 * R y$ ). From Fig. 1 it is clear that the material can absorb much more energy if its ductility is made use of.

To this purpose the European research project LISSAC (Limit Strains for Severe Accident Conditions) [1] has been carried out. In this project numerous mechanical tests on specimens of different shapes and sizes have been performed. The available test results can also provide information for other problems and questions in materials testing and research. One such question is the dependency of mechanical properties of metals on specimen size. These relations have been thoroughly studied for ceramics. For the fatigue properties of metals, empirical size factors have been used in design for many years, but since they are based on experience, little has been published on the theoretical background of size effects of mechanical properties of metals.

The available test results of LISSAC offer an opportunity to evaluate the volume dependency of mechanical properties of the material used for the tests. From the literature it is known that the statistical distribution of material properties using the Weibull distribution also can be used to include the volume dependency. Although this is well known, real data are scarce. The present evaluation adds experience and data in this field.

Manuscript received 23 June 2003; accepted for publication 18 March 2005; published Sept. 2005

${ }^{1}$ Senior Research Officer, Swiss Federal 1nstitute for Materials Testing and Research (EMPA), Ueberlandstr. 129, CH-8600, Duebendorf, Switzerland.

${ }^{2}$ FZK, Karlsruhe, Germany.

\section{Volume Effect in Weibull Distribution}

The Weibull distribution was developed first as a statistical distribution that would be flexible enough to describe different shapes of probability density distributions (e.g., in fatigue experiments). Later a scientific interpretation of this distribution was found-the theory of the weakest link. Since the Weibull distribution is very flexible, it has found wide use in reliability engineering. In many standard textbooks [2] an expression for the frequency of occurrence $P_{\mathrm{f}}$ of an event such as failure or reaching a stress or strain limit can be found, including the volume effect.

$$
P_{\mathrm{f}}(V)=1-\exp \left[-\left(\frac{\sigma}{\eta}\right)^{\beta} \frac{V}{V_{0}}\right]
$$

The probability of failure $P_{\mathrm{f}}$ depends on the strength $\sigma$ and on the volume tested $V$. The other parameters are the shape factor $\beta$ of the Weibull distribution and the scale factor $\eta$. $V_{0}$ is a reference volume. Instead of volume, length or area could be appropriate. This means that for materials having the same intrinsic failure behavior, the failure stresses depend on the volume of material under stress according to

$$
\frac{\bar{\sigma}_{1}}{\bar{\sigma}_{2}}=\left[\frac{V_{1}}{V_{2}}\right]^{-1 / \beta}
$$

For the present investigation we can replace stress by strain

$$
\frac{\varepsilon_{1}}{\varepsilon_{2}}=\left[\frac{V_{1}}{V_{2}}\right]^{-1 / \beta}
$$

\section{The LISSAC Project}

The current design rules for nuclear components allow only small structural deformations. They are appropriate for basic accident situations of the present design and rely on a stress-based concept. For extremely unlikely severe accidents, much larger plastic deformations with strains up to a certain fraction of the failure strain should be acceptable. In this case the analyses must use a more realistic 


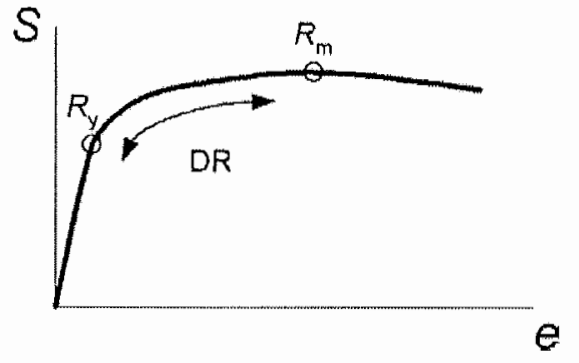

FIG. 1-Typical stress strain diagram of a medium strength steel in tension; the ductility reserve $D R$ extends over yield point $R_{y}$ to tensile strength $R_{m}$

strain-based concept. However, reliable information on local failure strains is not available.

Especially the influence of the component size on the failure strain is not known; but such information is indispensable if results from small-scale specimens and model tests are to be applied to dimensions of industrial components-e.g., pressure vessels of nuclear power plants. Therefore, the research project LISSAC has been launched to determine the failure strains and to propose admissible limit strains.

Based on the results from the present research program and from previous work, admissible strains can be proposed for different severe accident requirements.

\section{Experimental Work}

\section{Work Program}

The main part of the experimental work consisted of several test families with different specimen shapes under uniaxial and biaxial static and dynamic loads at room temperature (RT), at $400^{\circ} \mathrm{C}$, and at $850^{\circ} \mathrm{C}$. Within one test family, the specimen shapes and the other conditions were the same, but the sizes were varied up to the dimensions of real components. Special attention was given to test families in which the specimens had a hole or a notch causing nonuniform stress and strain distributions typical for local structural discontinuities-e.g., in reactor vessel components. There are indications that for such nonuniform distributions size effects may be more pronounced than for uniform distributions. Thus, the investigations should allow one to determine size effects on the failure strains and failure processes under conditions close to design configurations. Related discussions and preliminary results of the current project may be found in Ref 1 . As a main result, a proposal for admissible strains can be made.

\section{Material}

The material for the specimens was taken from the cylindrical section of an unused reactor pressure vessel BIBLIS-C made from quenched and tempered material 22NiMoCr 3 7. The location of the different specimens within the cylindrical section of the available reactor pressure vessel was determined such that specimens belonging to the same test family were grouped together as closely as possible. In this way the influence of spatial variations of the material properties on the results within one test family could be minimized.

In addition, specimens with thicknesses much smaller than the wall thickness, $t$, of the pressure vessel were located at the distance $t / 4$ from the outside surface of the reactor pressure vessel. Thus the reduced material strength usually found in the middle of the wall and the higher material strength at the surfaces of the wall did not appear in the smaller specimens. This means that the influence of variations of the material properties through the wall thickness of the pressure vessel has been minimized, too. To get more specific answers about the mechanical material properties and their scatter, Charpy impact tests and standard tension tests have been performed for selected positions. Since the carbon content is known to affect the mechanical material properties strongly, the spatial distribution of the carbon content in the cylindrical section of the reactor pressure vessel, from which the specimens were made, was investigated. The variations over the cylindrical surface of the vessel were found to be rather small. The variations through the wall thickness were greater. The influence of specmen orientation could be neglected.

From the available results, it can be concluded that the scatter of the material properties is rather moderate. Its effect on the material strength within one test family is expected to be in the order of magnitude of $\pm 1 \%$; its effect on the material ductility is expected to be in the range of $\pm 5 \%$.

\section{Test Matrix and Specimens}

Specimens-As mentioned before, several families of test specimens were designed to account for effects of size, stress concentration, and biaxiality. The thickness (diameter) of the tensile and bend specimens varied between 4 (3) and $200(150) \mathrm{mm}$. Figure 2 gives an overview of the different specimen types used. All specimens in different sizes were scaled.

The different specimen shapes under the listed load conditions define 22 test families (Table 1 ).

\section{Test Equipment and Procedure}

For the specimens, which vary strongly in shape, load, and size, very different testing machines were necessary. For the small tension tests standard machines were sufficient. However, the measurement of local maxima of strains required sophisticated methods such as the object raster technique. For the largest tension tests a very strong machine was needed, as shown in Fig. 3. For dynamic tension tests with well-defined strain rates, a machine was used in which the specimens were placed between very long prestressed

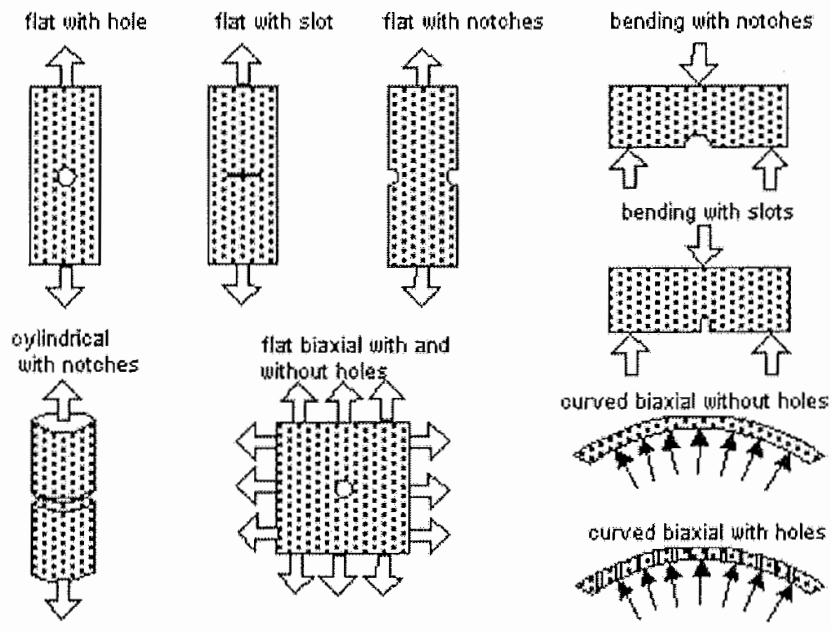

FIG. 2-Specimen types used for LISSAC. 
TABLE 1-Overview of shape and size of specimens and test temperatures.

\begin{tabular}{|c|c|c|c|c|c|c|}
\hline \multirow[b]{2}{*}{ Shape } & \multirow{2}{*}{$\begin{array}{c}\text { Stress } \\
\text { Concentration }\end{array}$} & \multirow[b]{2}{*}{ Test Speed } & \multicolumn{3}{|c|}{ Test Temperature } & \multirow[b]{2}{*}{ Thickness/Diameter, mm } \\
\hline & & & RT & $400^{\circ} \mathrm{C}$ & $850^{\circ} \mathrm{C}$ & \\
\hline flat & central hole & static & $x$ & $x$ & $x$ & $4-200$ \\
\hline flat & central hole increased & static & $x$ & & & $4-80$ \\
\hline flat & central slot & static & $x$ & & & $4-80$ \\
\hline flat & notches lateral & static & $x$ & $x$ & & $4-80$ \\
\hline bending & notch & static & $x$ & & & $4-80$ \\
\hline bending & slot & static & $x$ & & & $4-80$ \\
\hline cylindrical & notch & static & $\hat{x}$ & $x$ & $x$ & $3-150$ \\
\hline biaxial curved & no holes & static & $x$ & & & 5,25 \\
\hline biaxial curved & with holes & static & $x$ & & & 5,25 \\
\hline cylindrical & no notch & static & $x$ & & & 5 \\
\hline flat & central hole & dynamic & $x$ & $\times$ & $x$ & 4,20 \\
\hline cylindrical & notch & dynamic & $x$ & $\times *)$ & $x$ & 3,20 \\
\hline biaxial flat & no holes & dynamic & $x$ & & & 4 \\
\hline biaxial flat & with holes & dynamic & $x$ & & & 4,8 \\
\hline biaxial curved & no holes & dynamic & $x$ & & & 5,25 \\
\hline biaxial curved & with holes & dynamic & $x$ & & & 5,25 \\
\hline
\end{tabular}

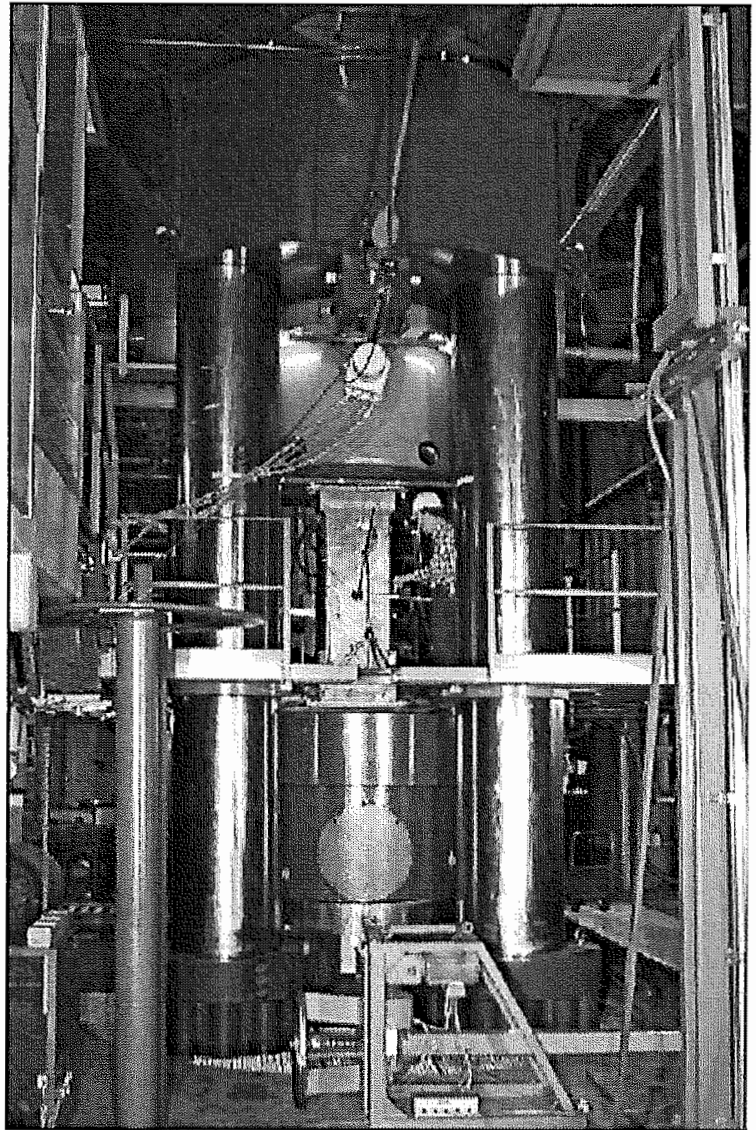

FIG. 3-100 MN test machine at MPA-Stuttgart (center: tensile specimen ready for testing).

steel cables. The dynamic load was provided by sudden release of the prestressing. Furthermore, a lot of additional test equipment and measuring techniques including microstructural investigations were applied. Since single institutions own only one or two of these facilities and have only a part of the expertise needed, the formation

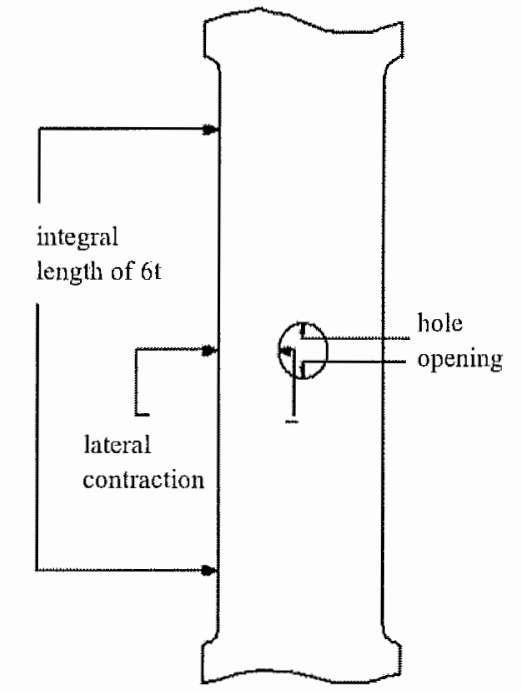

FIG. 4-Measurement of displacements, schematically.

of a consortium of different European institutions was a necessary prerequisite to perform the work.

If feasible, measuring grid lines were drawn on the surface of the specimens or reference points for displacement measurement were marked, or both.

Heating rate and time were controlled as well as the attainment of the required temperature around the test section. Small specimens were heated in an inert atmosphere of argon gas to avoid the development of oxide scales.

Measurement of deformations was carried out either by direct observation of the reference points using a video-extensometer or for tests at elevated temperatures by attaching levers and rods, clamps, and pin-points to the specimens, the displacement of which then was measured outside the temperature chamber; again by using a video-extensometer.

Figure 4 shows schematically how this worked and also the reference length of six times thickness or diameter $(6 t$ or $6 d)$ used for determination of overall strains. 


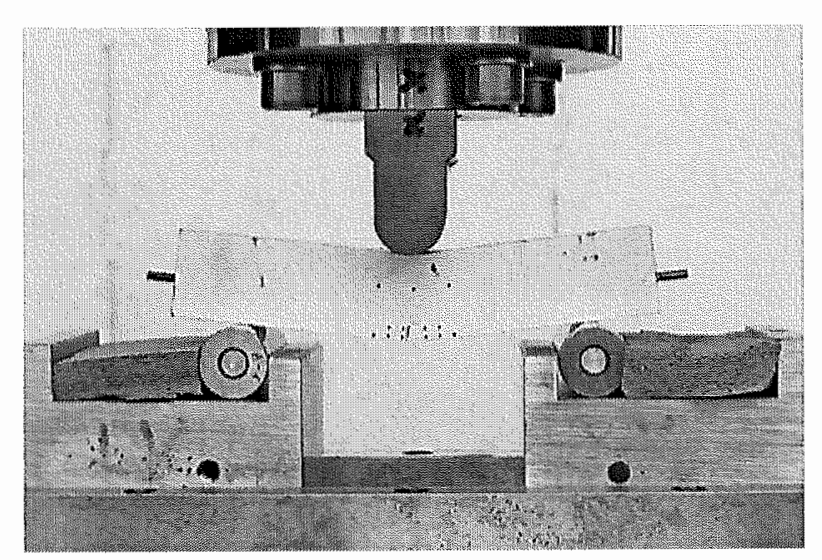

FIG. 5-Bend specimen with reference points for optical displacement measurements.

In Fig. 5 the reference points used for measurement of displacements in bend tests can be seen.

Failure was assumed to have occurred when a crack had reached a detectable size. This size typically was less than $10 \%$ of the wall thickness or of the diameter of the specimen. The local failure strain was defined as the maximum equivalent strain reached at the instant before the crack causes major strain redistributions.

The direct measurement of the local failure strain, i. e., the maximum equivalent strain at the instant when a crack can be just detected, is very difficult. For the LISSAC specimens with holes or notches, for instance, the maximum strain has a quite local character; it occurs at the curved surface of the hole or notch (inside the hole, for instance) and it reaches high values (often more than $100 \%)$. Thus strain gages can hardly be used. The application of markings and post-test measurements of the increased distances between these markings is only possible for large specimens. Also the application of a grid at the plane surface of a flat specimen with a hole or notches cannot really provide the maximum strain, which occurs at the curved surface of the hole or notch, but for large specimens the grid can be used to determine the strain distribution close to maximum.

\section{Methods to Determine the Local Failure Strain}

Because of the difficulties described above, indirect methods to determine the local failure strain have been developed within the
LISSAC project. They are based on post-test geometrical measurements on the broken specimens. The aim is to obtain a characteristic deformation $\delta$ of the specimen when a crack is just detectable. Based on this deformation, the related strain fields in the specimen then can be reconstructed using theoretical models such as finite-element models. For the different types of LISSAC specimens, appropriate indirect methods to determine the local failure strain were studied and applied.

For tension specimens with a hole or witl notches the so-called "vanishing gap method," which was developed in this project, was applied. In Fig. 6 the method is illustrated for a fiat specimen with a hole. The broken parts of the specimen are moved together such that the gap between the fracture surfaces vanishes. To reach this condition, most of the fracture zones of the broken specimen must overlap (Fig. $6 c$ ). It is assumed that the configuration obtained in this way represents the shape of the specimen at the instant when the crack has started to develop and is just detectable. The location of this starting crack is the position where the fracture surfaces contact each other. It is well known that the starting crack will be always perpendicular to the tension stress (normal fracture; e.g., Fig. 7). Therefore, during the search for the position of the starting crack, only elements of the fracture surfaces, which are approximately perpendicular to the tensile stress, must be considered. The relative vertical hole increase, the so-called hole opening at this instant, is defined as the characteristic deformation $\delta$.

This reconstruction would be correct, if during the process of crack propagation the deformed surfaces of the hole did not suffer further shape changes. Although a precise proof of this hypothesis is not yet available, basic considerations of the stress redistribution due to the propagating crack (no tension stress normal to the crack surfaces) strongly support the hypothesis. The major problem is that in reality the broken parts of the specimens cannot overlap because two bodies cannot occupy the same space. Thus the configuration shown in Fig. $6 c$ can be provided only virtually by computation.

\section{Experimental Results}

The material that was analyzed in LISSAC is a medium strength low alloy steel with the German designation 22NiMoCr 37 . This steel is comparable to the pressure vessel steel ASTM A 508 CI 2 and has been thoroughly tested many times. Chemical composition and results of tensile tests are shown in Tables 2 and 3.

Chemical Composition-In the LISSAC project the carbon content was analyzed in detail as an indicator of the locally different

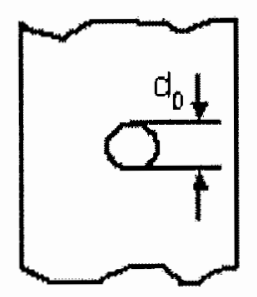

specimen before test

a

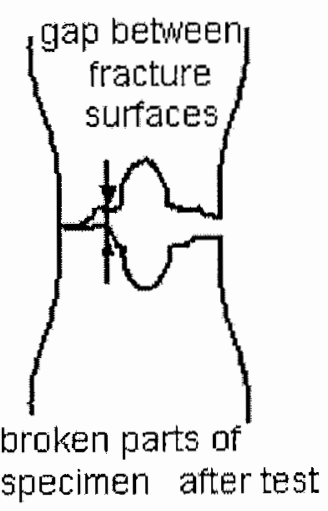

b)

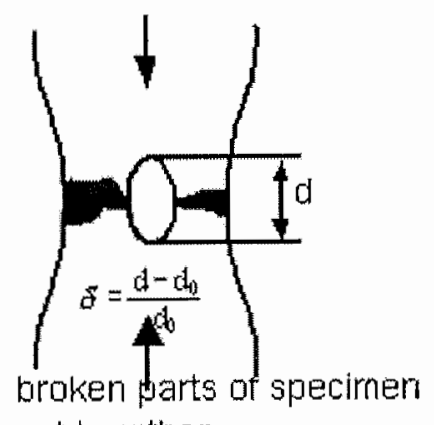

put together

FIG. 6-Principle of vanishing gap method (the hatched parts in picture c denote the fracture zone). 

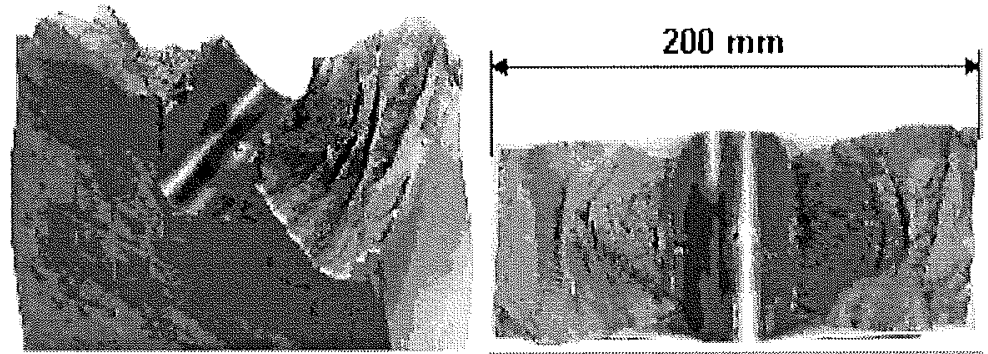

FIG. 7-Fracture surface of a broken flat specimen with a hole. Left: perspective view; Right: view in tension direction.

TABLE 2-Chemical composition of the test material (in wt \%).

\begin{tabular}{cccccccc}
\hline $\mathrm{C}$ & $\mathrm{Si}$ & $\mathrm{Mn}$ & $\mathrm{P}$ & $\mathrm{S}$ & $\mathrm{Ni}$ & $\mathrm{Cr}$ & $\mathrm{Mo}$ \\
\hline 0.22 & 0.19 & 0.89 & 0.007 & 0.007 & 0.87 & 0.40 & 0.55 \\
\hline
\end{tabular}

TABLE $3-$ Results of tensile tests with $5 D$ specimens, $D=5 \mathrm{~mm}, R T$ $\left(20^{\circ} \mathrm{C}\right)$.

\begin{tabular}{lccc}
\hline Property & Test Results & Standard Values & \\
\hline$R_{\mathrm{p} 0.2}$ & $434($ sdev 13) & $>392$ & $\mathrm{MPa}$ \\
$R_{\mathrm{m}}$ & $590($ sdev 11) & $>559$ & $\mathrm{MPa}$ \\
$A_{5}$ & $25.6($ sdev 1.5$)$ & $>17$ & $\%$ \\
$Z$ & $73.3($ sdev 1.5$)$ & $>38$ & $\%$ \\
\hline
\end{tabular}

$A_{5}$ is the elongation after fracture for a gap length of five diameters and $Z$ is the reduction of area.

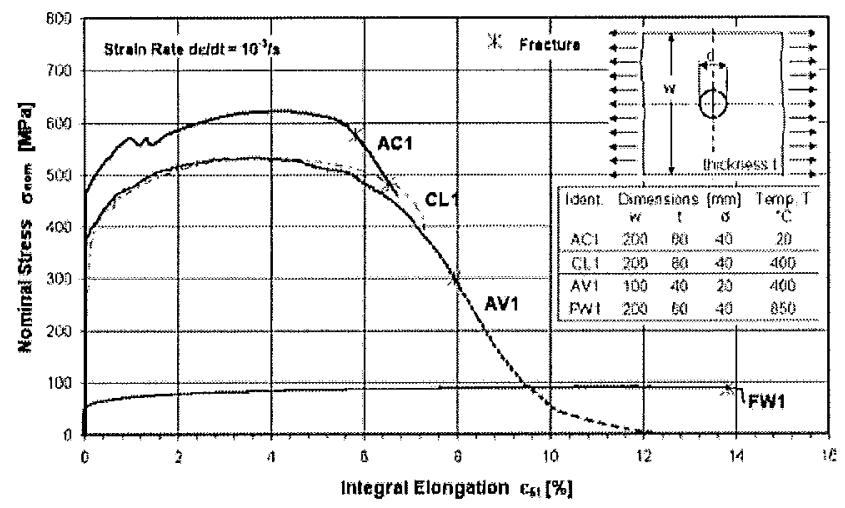

FIG. 8-Results of tensile tests on specimens with a central hole at different temperatures.

distribution of the alloying elements in the large forged component from which the specimens were manufactured.

Tensile Test-The test results (see Fig. 8) show that maximum load is not influenced by size and that the difference of maximum load between tests at room temperature and at $400^{\circ} \mathrm{C}$ is nearly negligible, compared to that at $850^{\circ} \mathrm{C}$. Size seems to be important for the strain at which fracture becomes apparent, as marked by asterisks in Fig. 8.

For each test the two characteristic strains, $\delta$ and $\varepsilon$, have been determined. The first strain, $\delta$, is a characteristic deformation of the specimen at failure, mostly obtained in a post-test measurement process. For the flat, the bending, and the cylindrical specimens it is the relative hole or notch opening; for the flat and curved biaxial specimens it is the strain in the thickness direction as described previously. For the smooth circular specimens (without notch) it is the cross-section reduction. The second strain, $\varepsilon$, is the maximum local equivalent strain at failure and is calculated by the standard relations given in the basic literature on mechanics.

The methods applied to determine $\delta$ and $\varepsilon$ were:

1. a. vanishing gap method, three-dimensional measuring machine

b. vanishing gap method, optical triangulation

c. vanishing gap method, inserting plastic material usually used in dentistry

d. vanishing gap method, direct measurement of the hole or notch opening

2. cross section reduction method

3. forging die method

4. thickness reduction method

5. visual inspection during testing

In Table 4 the results of more than 250 static tests on flat and cylindrical specimens at different temperatures have been compiled.

The applicability of the resulting higher limit strains leading to a reduction of current over-conservatism has been demonstrated for some selected severe accident problems. One important example is the corium slug impact against the pressure vessel head during a postulated in-vessel steam explosion. In previous investigations, only minor strains in the pressure vessel head were allowed and on this basis the load carrying capacity of the head in terms of kinetic slug energies was limited to $0.1,0.4$, and 0.8 GJ, depending on the conditions of the upper internal structures. As a result of the project LISSAC, larger admissible strains in the head can be allowed for a material such as that used for the LISSAC test. The increased load-carrying capacity in terms of kinetic slug energies can be determined. Another example might be the pressure vessel clamping, which should withstand the dynamic loading caused by a postulated lower head failure, for instance.

For each test both of the limit strains, $\varepsilon$ and $\delta$, have been analyzed using a Weibull distribution, and the shape factor $\beta$ and scale factor $\eta$, as well as the coefficient of correlation $r^{2}$, shown in Table 4, have been determined. These evaluations have been performed using software provided by Ref 3 and described in detail in Ref 4 .

All results from flat and cylindrical specimens are plotted together in a two-parameter Weibull plot shown in Fig. 9. Apparently the results for failure strain $\varepsilon$ at room temperature (RT) and at $400^{\circ} \mathrm{C}$ are nearly identical concerning the shape and the scale factor. The slightly smaller slope for $850^{\circ} \mathrm{C}$ possibly indicates a change to a different failure mode. 
TABLE 4—Results of analysis of LISSAC tests using a Weibull distribution.

\begin{tabular}{|c|c|c|c|c|c|c|c|c|}
\hline \multirow[b]{2}{*}{ Specimen } & \multirow[b]{2}{*}{ Thickness, mm } & \multirow[b]{2}{*}{ Temperature ${ }^{\circ} \mathrm{C}$} & \multicolumn{3}{|c|}{$\varepsilon$} & \multicolumn{3}{|c|}{$\delta$} \\
\hline & & & $\beta$ & $\eta$ & $r^{2}$ & $\beta$ & 11 & $r^{2}$ \\
\hline \multirow[t]{6}{*}{ flat central hole } & 4 & RT & 16.25 & 86.47 & 0.77 & 15.4 & 143.5 & 0.81 \\
\hline & 20 & RT & 24.7 & 66.0 & 0.91 & 29.2 & 105.1 & 0.87 \\
\hline & 4 & 400 & 9 & 81.4 & 0.76 & 8.0 & 134.4 & 0.73 \\
\hline & 20 & 400 & 7.6 & 51.3 & 1 & 10.1 & 83.3 & 1 \\
\hline & 4 & 850 & 21.3 & 69.8 & 0.99 & 28.5 & 76.5 & 0.9 \\
\hline & 20 & 850 & 25.4 & 75.2 & 1 & 25.8 & 82.3 & 1 \\
\hline \multirow{2}{*}{ flat increased central hole } & 4 & RT & 20.7 & 55.25 & 0.86 & 13.8 & 139.4 & 0.87 \\
\hline & 20 & RT & 30.4 & 46.5 & 0.68 & 16.7 & 110.9 & 0.68 \\
\hline \multirow[t]{2}{*}{ flat central slot hole } & 4 & RT & 5.7 & 209.1 & 0.97 & 7.33 & 167.2 & 0.95 \\
\hline & 20 & RT & 23.4 & 136.6 & 0.93 & 41.6 & 119.3 & 0.94 \\
\hline \multirow[t]{5}{*}{ cylindrical notched } & 4 & RT & 5.1 & 117.4 & 0.92 & 5.5 & 154.6 & 0.91 \\
\hline & 9 & RT & 36.4 & 109.4 & 0.98 & 36.6 & 144.1 & 0.98 \\
\hline & 20 & RT & 110.5 & 85.6 & 1 & 173.8 & 113.8 & 1 \\
\hline & 4 & 400 & 11.6 & 126.4 & 0.93 & 11.4 & 164.7 & 0.92 \\
\hline & 9 & 400 & 13.4 & 110.9 & 0.99 & 15.1 & 144.8 & 0.90 \\
\hline
\end{tabular}

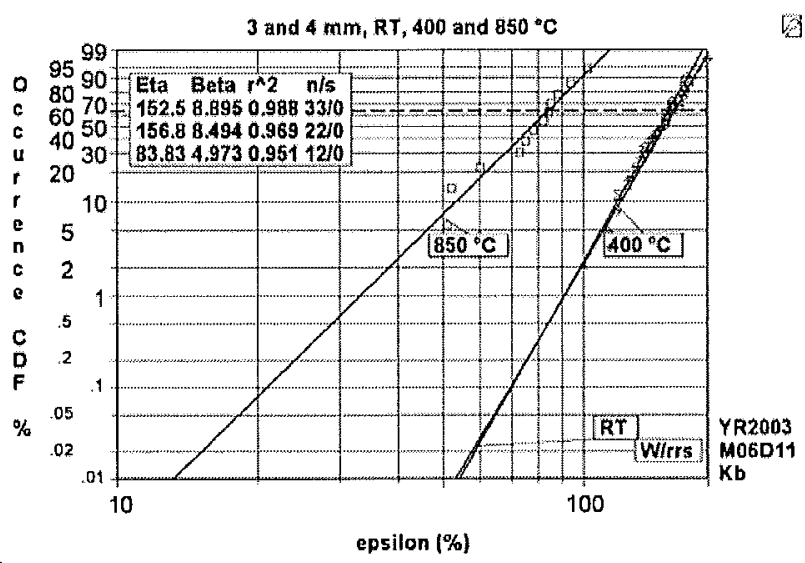

FIG. 9-Weibull plot of tests with small specimens ( 3 and 4 mm thick) at $R T, 400^{\circ} \mathrm{C}$, and $850^{\circ} \mathrm{C}$.

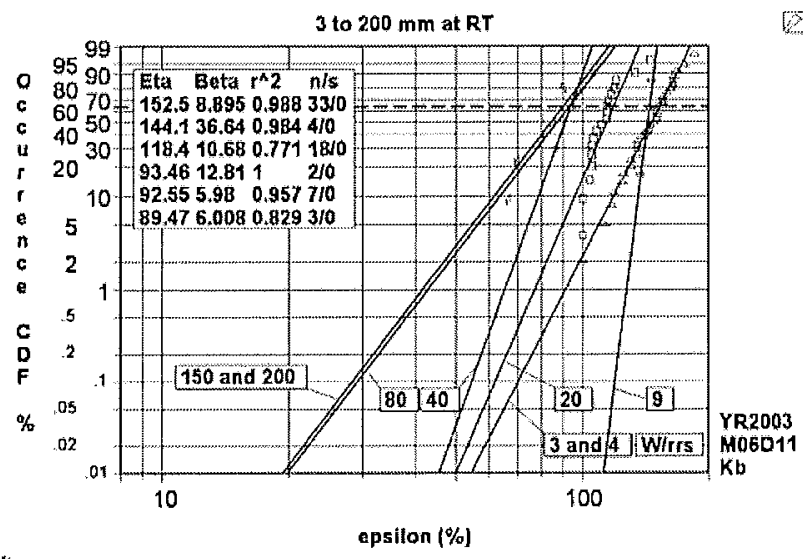

FIG. 10-Weibull plot of tests with specimens 3-200 mm thick at RT.

The size effect at the different test temperatures is mainly visible in the values of the scale factor $\eta$, i.e., the location of the limit strain for $63 \%$ probability of failure. Whereas the shape factors all

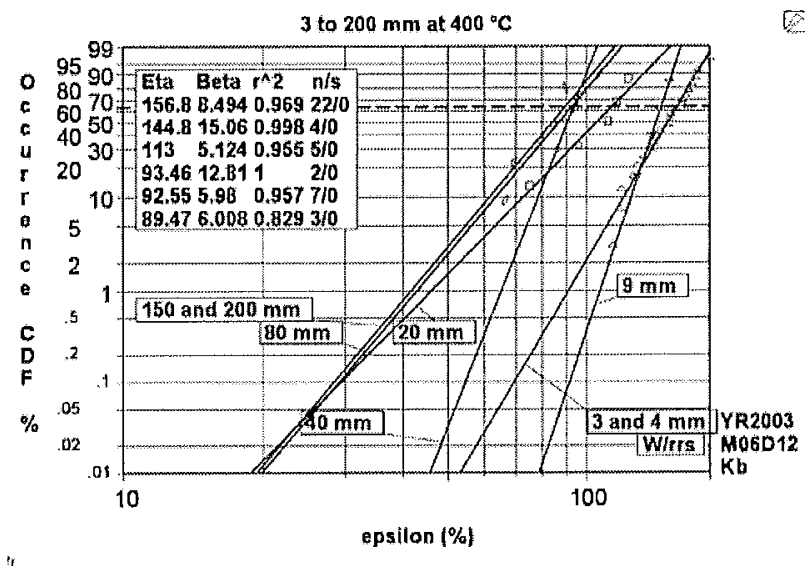

FIG. 11-Weibull plot of tests with specimens $3-200 \mathrm{~mm}$ thick at $400^{\circ} \mathrm{C}$.

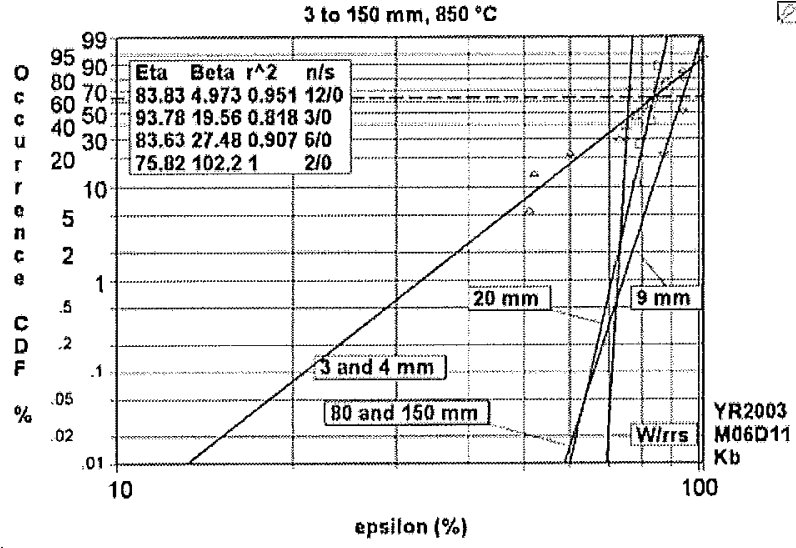

FIG. 12-Weibull plot of tests with specimens 3-200 mm thick at $850^{\prime \prime} \mathrm{C}$.

appear to be grouped according to size for specimens between 9 and $150 \mathrm{~mm}$, this is not the case for the smallest specimens ( 3 and $4 \mathrm{~mm}$ thick). This is clearly visible in Figs. 10-12. 
TABLE 5-Confidence limits for limit strain $\varepsilon$ for 63,50 , and $0.01 \%$ failure probability.

\begin{tabular}{lccc}
\hline \multicolumn{1}{c}{$t[\mathrm{~mm}]$} & $\varepsilon(p=63 \%)$ & $\varepsilon(p=50 \%)$ & $\varepsilon(p=0.01 \%)$ \\
\hline 3 and 4 & 152.5 & 146.5 & 54.5 \\
9 & 144.1 & 143.3 & 112.5 \\
20 & 118.4 & 114 & 49.9 \\
40 & 93.5 & 90.7 & 45.5 \\
80 & 92.6 & 87.6 & 20.0 \\
150 and 200 & 89.5 & 83.8 & 19.5 \\
\hline
\end{tabular}

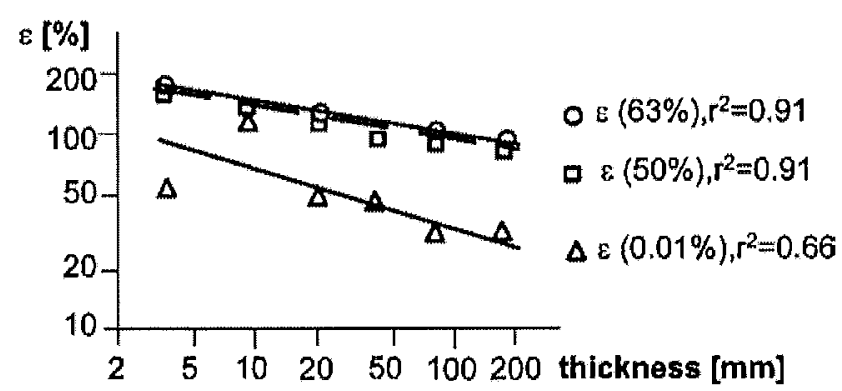

FIG. 13-Strain limit for the collected tests with different confidence levels derived from the Weibull plots.

If a lower bound of $\delta=36 \%$ is used, the coefficient of correlation $r^{2}$ is 0.99 , meaning that the Weibull relation is a good fit. From the Weibull plots of the specimens sized 3-200 $\mathrm{mm}$ and tested at room temperature, one can extract specific $\varepsilon$-values shown in Table 5 . Here the $\eta$ for $63 \%, 50 \%$, and $0.01 \%$ probability of occurrence was determined. For the individual plots the coefficient of regression $r^{2}$ was between 0.8 and 1.0, as Figs. 9-12 show.

In Fig. 13 these results are plotted against the corresponding specimen thickness. The trend is obviously a decrease of the limit strains $\varepsilon$ with increasing specimen thickness. Whereas the approximation by a power relation seems to be quite good for probabilites of 63 and $50 \%$ for $\varepsilon$, the coefficient of correlation is lower for a probability of $0.01 \%$. This is obviously a consequence of the larger scatter for low probablities due to the limited number of test results available and the larger scatter of the shape factor $\beta$ of the Weibull distributions.

$$
P(\varepsilon)=1-\exp \left[-\left(\frac{\varepsilon-\varepsilon_{0}}{\eta-\varepsilon_{0}}\right)^{\beta}\left(\frac{V}{V_{0}}\right)\right]
$$

Now a comparison between the test results and the prediction by the Weibull size theory can be made. Assuming $\varepsilon_{0}=0$ and $V / V_{0}=$ $\left(t / t_{0}\right)^{3}$ in Eq 3, one can predict $\varepsilon$ for given $\beta$ and $\eta$ for a specimen thickness different from $t_{0}$.

From $P(\varepsilon)$, after some transformations, one gets

$$
\ln \left[\ln \left(\frac{1}{1-P(\varepsilon)}\right)\right]=\beta \ln \left(\frac{\varepsilon}{\eta}\right)+3 \ln \left(\frac{t}{t_{0}}\right)
$$

and

$$
\varepsilon=\eta_{0}\left(\frac{t}{t_{0}}\right)^{-3 / \beta_{0}}
$$

Using the values of the smallest specimens with a mean thickness of $3.5 \mathrm{~mm}$ as reference, one gets the results in Table 6 . The comparison is based on $\eta_{0}=152.5 \%, \beta_{0}=8.9$, and $t_{0}=$ $3.5 \mathrm{~mm}$.

From this table it can be seen that the size effect can be only qualitatively modelled by the Weibull relation with the theoretical Weibull parameters. If either the volume effect is decreased by decreasing the exponent for thickness from 3 to 1.2 or increasing the Weibull exponent $\beta$ from that of the reference thickness to a mean value or higher, the experimental values can also be calculated by Eq 5 .

\section{Comparison of Test Results and Weibull Model and Conclusions}

First, from the test results the parameters of the corresponding Weibull distributions are derived as shown in Figs. 9-12. With these parameters and the Weibull function for volume dependency, the failure probability corresponding to the individual volumes can be predicted. Now the measured and the predicted failure probabilities can be compared, as done in Table 5 . The comparison shows that the theoretical limit strains $\varepsilon_{\text {th }}$ for specimens larger than the reference size can be predicted only with a sufficient accuracy if in Eq 5 the exponent is assumed to be approximately one. This can be interpreted as a dependency of the limit strain on a onedimensional parameter such as thickness or notch size rather than on three-dimensional volume. If nevertheless a volume dependency is assumed, a shape factor of the Weibull distribution of approximately 20 is necessary to bring experimental and theoretical results to correspondence.

\begin{tabular}{|c|c|c|c|c|c|}
\hline$t, \mathrm{~mm}$ & $\begin{array}{c}\varepsilon_{\exp }(63 \%) \\
\text { Experimental }\end{array}$ & $\begin{array}{c}\varepsilon_{\mathrm{th}} \\
\text { (with exponent } \\
3 \text { and } \beta_{0}=8.9 \text { ) }\end{array}$ & $\begin{array}{c}\varepsilon_{\mathrm{th}_{1}} \\
\text { (with exponent } \\
1.2 \text { and } \beta_{0}=8.9 \text { ) }\end{array}$ & $\begin{array}{c}\varepsilon_{\mathrm{th}} \\
\text { (with exponent } \\
3 \text { and } \beta_{0}=13.5 \text { ) }\end{array}$ & $\begin{array}{c}\varepsilon_{\mathrm{th}} \\
\text { (with exponent } 3 \\
\text { and } \beta_{0}=20 \text { ) }\end{array}$ \\
\hline 3.5 & 152.5 & 152.5 & 152.5 & 152.5 & 152.5 \\
\hline 9 & 144.1 & 110.9 & 134.3 & 123.6 & 132.4 \\
\hline 20 & 118.4 & 84.7 & 120.6 & 103.5 & 117.4 \\
\hline 40 & 93.5 & 67.1 & 109.8 & 88.7 & 105.8 \\
\hline 80 & 92.6 & 53.1 & 100.0 & 76.1 & 95.4 \\
\hline 175 & 89.5 & 40.8 & 90.0 & 63.9 & 84.8 \\
\hline
\end{tabular}

TABLE 6-Comparison of experimental limit strains $\varepsilon_{\text {exp }}$ with the theoretical values $\varepsilon_{t h}$ for different exponents accounting for the volume effect and different Weibull factors $\beta$. 


\section{Acknowledgment}

The sponsoring and financial support of this project by the European Commission under contract number FIKS-CT 1999-00012 is gratefully acknowledged.

\section{References}

[1] Limit Strains for Severe Accident Conditions (LISSAC), 5th EU Framework Programme, Contract FIKS-CT1999-00012, final report by R. Krieg, Research Center Karlsruhe (FZK), Karlsruhe 2003.

[2] Wachtmann, J. B., Mechanical Properties of Ceramics, John Wiley \& Sons, 1996.

[3] Winsmith ${ }^{T M}$ Weibull $4 M-32$, Software for Weibull evaluations, Fulton Findings ${ }^{\mathrm{TM}}, 1251 \mathrm{~W}$ Sepulveda Blvd., PMB 800, Torrance, CA 90502, www.weibullnews.com.

[4] Abernethy, Robert B., The New Weibull Handbook, selfpublished, 536 Oyster Road, North Palm Beach, Florida 33408$4328,1992$. 